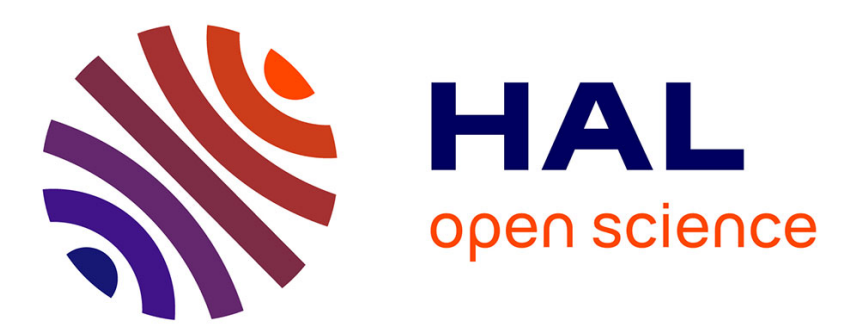

\title{
Magnetically assisted delivery of cells using a magnetic resonance imaging system
}

J Riegler, B Allain, R J Cook, M F Lythgoe, Q A Pankhurst

\section{To cite this version:}

J Riegler, B Allain, R J Cook, M F Lythgoe, Q A Pankhurst. Magnetically assisted delivery of cells using a magnetic resonance imaging system. Journal of Physics D: Applied Physics, 2011, 44 (5), pp.55001. 10.1088/0022-3727/44/5/055001 . hal-00591290

\section{HAL Id: hal-00591290 \\ https://hal.science/hal-00591290}

Submitted on 9 May 2011

HAL is a multi-disciplinary open access archive for the deposit and dissemination of scientific research documents, whether they are published or not. The documents may come from teaching and research institutions in France or abroad, or from public or private research centers.
L'archive ouverte pluridisciplinaire HAL, est destinée au dépôt et à la diffusion de documents scientifiques de niveau recherche, publiés ou non, émanant des établissements d'enseignement et de recherche français ou étrangers, des laboratoires publics ou privés. 


\title{
Magnetically assisted delivery of cells using a magnetic resonance imaging system
}

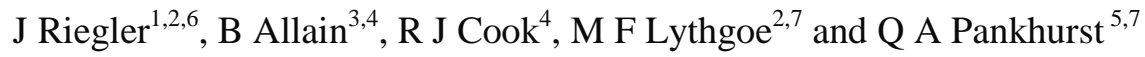 \\ ${ }^{1}$ Centre for Advanced Biomedical Imaging (CABI), Department of Medicine and Institute of Child \\ Health, University College London (UCL), London WC1E 6DD, UK \\ ${ }^{2}$ Centre for Mathematics and Physics in the Life Sciences and Experimental Biology (CoMPLEX), \\ UCL, London WC1E 6BT, UK \\ ${ }^{3}$ KCL Dental Institute, Biomaterials, Biomimetics and Biophotonics Group, C/O Floor 17 Tower \\ Wing, Guy's Hospital Campus, Great Maze Pond, London SE1 9RT, UK \\ ${ }^{4}$ Centre for Medical Image Computing (CMIC) UCL, London WC1E 6BT, UK \\ ${ }^{5}$ Davy-Faraday Research Laboratory, The Royal Institution of Great Britain, 21 Albemarle Street, \\ London W1S 4BS, United Kingdom \\ ${ }^{6}$ corresponding author \\ ${ }^{7}$ joint last author \\ E-mail: j.riegler@ucl.ac.uk
}

Running title:

Magnetic cell targeting with MRI

\begin{abstract}
A simple analytical model is presented which enables rapid interactive prediction and control of magnetically labelled cells in an arterial bifurcation using magnetic field gradients produced by a magnetic resonance imaging system (MRI). This model is compared against experimental results for human mononuclear cells labelled with micron sized superparamagnetic iron oxide particles. Experimental and theoretical results highlight the importance of cell aggregation for magnetic targeting in a strong magnetic field. These predicted aggregates are confirmed via confocal endoscopy which allows the visualisation of cell aggregates and their movement inside a vascular flow model in a $9.4 \mathrm{~T}$ preclinical MRI scanner.
\end{abstract}




\section{Introduction}

The increased understanding of cellular processes and the role of cells during embryonic development and regeneration has opened new research avenues for cell transplantation therapies. These cell therapies use a variety of cell types from terminally differentiated cells such as T-cells [1] to embryonic stem cells [2]. Several clinical trials are already investigating the potential of adult stem cells contained in the bone marrow for cardiac repair after myocardial infarction as well as other possible applications [3-7].

The efficacy of such treatments is determined by many factors such as cell type, differentiation potential, delivery route, delivery time, local micro-environment, inflammation, cell retention etc. Current approaches for cell delivery and retention frequently end up achieving less than $10 \%$ retention of administered cells [8]. Magnetically assisted delivery is one of a range of strategies proposed to address this issue.

Magnetic targeting strategies rely on the fact that cells which have been made responsive to magnetic fields by internalisation of iron oxide particles can be steered over a distance using magnetic fields [9]. Particles used for such applications exhibit superparamagnetism due to their size. As other cells in the body do not contain sufficient amounts of magnetic materials only labelled cells are affected and can be concentrated and retained in the target area. In order to concentrate magnetic particles or cells in an area, a magnetic field and a field gradient is necessary [9]. These can be generated by a number of sources including permanent magnets outside of the body, implanted magnets or permanent/electro magnets external to the body in combination with ferromagnetic materials such as needles or stents to generate high field gradients. A general limitation of magnetic targeting, especially for permanent magnets and electromagnets positioned outside of the body is the rapid decay of the magnetic force with increasing distance from its source, which follows an inverse square relation. This rapid decay of the magnetic field strength and gradient strength, leads to a parallel decay of magnetic forces, limiting its applicability to organs close to the body surface [10-14].

A potential alternative was proposed and explored by Mathieu and Martel [15-17]. In experiments on live pigs, they were able to actuate and steer an intravenously introduced $1.5 \mathrm{~mm}$ steel ball through parts of the porcine vascular network by manipulating the gradient coil currents of a standard 1.5T magnetic resonance imaging (MRI) system. By doing so they were able to successfully demonstrate the concept of magnetic resonance targeting (MRT), viz. magnetically assisted delivery using an MRI system; although it could be argued that they did not establish the feasibility of MRT in man, as the use of such large steel objects is inconceivable due to the risk of thrombosis.

Nevertheless, if a variant of MRT could be made to work in man, it could be highly advantageous and useful. To this end, we have been exploring the use of magnetically labelled cells. In recent work we have shown that substantial actuation forces can be generated on such cells [18], at a level that makes them suitable for MRT. In principle one can then imagine a viable human therapeutic procedure in which, for example, a patient's own stem cells could be harvested, magnetically labelled, and then re-introduced into the bloodstream, where their unchanged membrane characteristics would ensure biocompatibility, while the internalised magnetic particles would render them suitable for magnetically assisted delivery.

Furthermore, there are at least four major advantages in using magnetically labelled cells and the gradient coils in MRI systems for targeting applications. (1) The high magnetic field strength (more than $1.0 \mathrm{~T}$ ) ensures the full magnetisation of the magnetic particles in the cells, and maximises their actuation potential. (2) The high spatial and temporal control over the gradient strength and direction in MRI systems allows high-precision and active guidance of particles along a chosen path. (3) The conventional use of MRI systems to generate high contrast soft tissue images can be combined with the targeting application to both guide the magnetically labelled cells to the area of interest and to monitor their accumulation at the target over time. (4) MRI systems are widely available in hospitals and clinics all over the world, so that the development of a delivery method based on MRT would be similarly widely available, without the need for major capital expenditure on new equipment.

We are therefore continuing our exploration of the feasibility of MRT on magnetically labelled cells as a potential human therapeutic intervention. In the current study we focus on an important aspect of the magnetically assisted delivery process itself, namely the ability to understand and predict the direction of motion of magnetically labelled cells in the vasculature. We start from the principle 
that the best way to achieve this is to derive a simple analytical model, and preferably an algebraic one, to allow rapid and interactive processing as part of the MRT process. In the following we show that this is possible, and we derive a simple analytical model describing magnetic cell steering in an MRI scanner. We introduce several practical concepts to assist in the cell tracking and steering process, including a weighting factor to account for both the cell distribution in a tube that is projected into a 2D plane, and the presence of prolate spheroids to account for cell aggregation. We compare this model against experimental results and highlight the importance of cell aggregation at lower flow rates. In order to confirm these predictions we used confocal endoscopic imaging inside and outside the bore of the MRI scanner to visualise cell distribution and aggregation. 


\section{An analytical model of magnetically assisted cell delivery in an MRI system}

The movement of suspended cells in a magnetic field is primarily governed by the magnetic force, drag force, gravity, inertia and magnetic dipole interactions. The model described below takes the magnetic force and drag force into account while inertia and gravity are ignored. Magnetic dipole interactions are indirectly included by assuming cells aggregating to bigger objects. The assumption of cell aggregation and factors influencing it, such as cell concentration, viscosity and fluid velocity will be experimentally parameterised and assessed later (see section 3.1 and 3.2), while the influence of aggregate shapes will be theoretically assessed (see section 4.5).

\subsection{Magnetic field}

The main driving force for cell movement inside of the MRI scanner is the field gradient produced by the coils used to generate the imaging gradients. The magnetic field $\boldsymbol{B}$ can be described using Maxwell's equations:

$$
\begin{aligned}
& \nabla \cdot \boldsymbol{B}=0, \text { and } \\
& \nabla \times \boldsymbol{B}=\mu_{0} \varepsilon_{0} \frac{\partial \boldsymbol{E}}{\partial t}+\mu_{0} \boldsymbol{J}
\end{aligned}
$$

where $\mu_{0}$ and $\varepsilon_{0}$ are the magnetic and electric permeabilities of free space, $\boldsymbol{E}$ the electric field and $\boldsymbol{J}$ the current density. The bore of an MRI scanner is a source free field which means that there are no electric fields or currents present. Accordingly equation 2 reduced to:

$$
\nabla \times \mathbf{B}=0
$$

Equations 1 and 3 can be rewritten in their component forms as:

$$
\begin{aligned}
& \frac{\partial B_{x}}{\partial x}+\frac{\partial B_{y}}{\partial y}+\frac{\partial B_{z}}{\partial z}=0, \text { and } \\
& \left(\frac{\partial B_{z}}{\partial y}-\frac{\partial B_{y}}{\partial z}\right) i+\left(\frac{\partial B_{z}}{\partial x}-\frac{\partial B_{x}}{\partial z}\right) j+\left(\frac{\partial B_{y}}{\partial x}-\frac{\partial B_{x}}{\partial y}\right) k=0 . \\
& \frac{\partial B_{z}}{\partial y}=\frac{\partial B_{y}}{\partial z} \\
& \frac{\partial B_{z}}{\partial x}=\frac{\partial B_{x}}{\partial z} \\
& \frac{\partial B_{y}}{\partial x}=\frac{\partial B_{x}}{\partial y}
\end{aligned}
$$

Equations 4 and 5 contain five independent derivatives. The first three of them can be selected as the linear field gradients which are derivatives of $B_{z}$ as the main field is orientated along the $z$-axis in $M R$ systems:

$$
\mathrm{g}_{\mathrm{x}} \equiv \frac{\partial \mathrm{B}_{\mathrm{z}}}{\partial \mathrm{x}} ; \quad \mathrm{g}_{\mathrm{y}} \equiv \frac{\partial \mathrm{B}_{\mathrm{z}}}{\partial \mathrm{y}} ; \quad \mathrm{g}_{\mathrm{z}} \equiv \frac{\partial \mathrm{B}_{\mathrm{z}}}{\partial \mathrm{z}} .
$$

For a symmetrical $\mathrm{z}$ gradient $\left(\mathrm{g}_{\mathrm{z}}\right)$ in a cylindrical coordinate system $\partial \mathrm{B}_{\mathrm{x}} / \partial \mathrm{x}$ and $\partial \mathrm{B}_{\mathrm{y}} / \partial \mathrm{y}$ should be identical. We can therefore introduce a symmetry parameter $\alpha$ :

$$
\alpha \equiv-\frac{\partial \mathrm{B}_{\mathrm{x}} / \partial \mathrm{x}}{\mathrm{g}_{\mathrm{z}}} ; \quad 1-\alpha \equiv-\frac{\partial \mathrm{B}_{\mathrm{y}} / \partial \mathrm{y}}{\mathrm{g}_{\mathrm{z}}} .
$$

As the last independent variable we can chose equation $5 \mathrm{c}$ :

$$
\beta \equiv \frac{\partial \mathrm{B}_{\mathrm{y}}}{\partial \mathrm{x}}=\frac{\partial \mathrm{B}_{\mathrm{x}}}{\partial \mathrm{y}} \text {. }
$$

All the partial derivatives described in Equations 4 and 5 can be expressed with the independent variables described in Equations 6,7 and 8. The field produced by the gradient coils can then be expressed as:

$$
\left[\begin{array}{l}
\mathrm{B}_{\mathrm{x}} \\
\mathrm{B}_{\mathrm{y}} \\
\mathrm{B}_{\mathrm{z}}
\end{array}\right]=\left[\begin{array}{ccc}
\frac{\partial \mathrm{B}_{\mathrm{x}}}{\partial \mathrm{x}} & \frac{\partial \mathrm{B}_{\mathrm{x}}}{\partial \mathrm{y}} & \frac{\partial \mathrm{B}_{\mathrm{x}}}{\partial \mathrm{z}} \\
\frac{\partial \mathrm{B}_{\mathrm{y}}}{\partial \mathrm{x}} & \frac{\partial \mathrm{B}_{\mathrm{y}}}{\partial \mathrm{y}} & \frac{\partial \mathrm{B}_{\mathrm{y}}}{\partial \mathrm{z}} \\
\frac{\partial \mathrm{B}_{\mathrm{z}}}{\partial \mathrm{x}} & \frac{\partial \mathrm{B}_{\mathrm{z}}}{\partial \mathrm{y}} & \frac{\partial \mathrm{B}_{\mathrm{z}}}{\partial \mathrm{z}}
\end{array}\right]\left[\begin{array}{c}
\mathrm{x} \\
\mathrm{y} \\
\mathrm{z}
\end{array}\right]=\left[\begin{array}{ccc}
-\alpha \mathrm{g}_{\mathrm{z}} & \beta & \mathrm{g}_{\mathrm{x}} \\
\beta & -(1-\alpha) \mathrm{g}_{\mathrm{z}} & \mathrm{g}_{\mathrm{y}} \\
\mathrm{g}_{\mathrm{x}} & \mathrm{g}_{\mathrm{y}} & \mathrm{g}_{\mathrm{z}}
\end{array}\right]\left[\begin{array}{l}
\mathrm{x} \\
\mathrm{y} \\
\mathrm{z}
\end{array}\right] .
$$

For MRI gradient coils $\beta \approx 0$ and due to the cylindrical geometry $\alpha=1 / 2$. Equation 9 can therefore be simplified to: 


$$
\left[\begin{array}{c}
B_{x} \\
B_{y} \\
B_{z}
\end{array}\right]=\left[\begin{array}{c}
-\frac{1}{2} g_{z} x+g_{x} z \\
-\frac{1}{2} g_{z} y+g_{y} z \\
g_{z} x+g_{y} y+g_{z} z
\end{array}\right],
$$

which is an especially convenient algebraic expression for the magnetic field in MRI systems [19], as it is common practice for scanner manufacturers to supply data on $g_{x}, g_{y}$, and $g_{z}$ amongst the specifications of their instruments (for field maps see figure 1).

In addition Equation 10 shows explicitly that gradients along the $\mathrm{x}$ - and $\mathrm{y}$-axes are produced by the $B_{z}$ field. Hence we can have a magnetic force along those axes despite the magnetisation of material introduced into the field of the scanner being solely along the z-axis.

\section{2 Magnetic force on cells}

The magnetic force acting on a particle is dependent on its magnetic susceptibility, the field strength and the gradients of the field, which can be expressed as:

$$
\begin{aligned}
& \boldsymbol{F}_{m}=(\boldsymbol{m} \cdot \nabla) \boldsymbol{B}, \text { and } \\
& \boldsymbol{m}=\frac{V \Delta \chi \boldsymbol{B}}{\mu_{0}}
\end{aligned}
$$

where $V$ is the particle volume and $\Delta \chi$ is the magnetic susceptibility difference between the particle and its surrounding fluid.

This equation can be simplified for the case of MRT of cells since the magnetic particles will be fully magnetised due to the strong $B_{0}$ field of the scanner. We can therefore simplify equations 11 and 12 to:

$$
\boldsymbol{F}_{m}=N V\left(\boldsymbol{M}_{\boldsymbol{s}} \cdot \boldsymbol{\nabla}\right) \boldsymbol{B}
$$

where $N$ is the number of magnetic particles in a cell and $\boldsymbol{M}_{\boldsymbol{s}}$ is the saturation magnetisation for a magnetic particle. As the magnetisation of particles in an MRI scanner is mainly along the z-axis, the $\mathrm{x}$ and $\mathrm{y}$ magnetisation components can be neglected reducing Eq. 13 to:

$$
\left[\begin{array}{lll}
F_{m, x} & F_{m, y} & F_{m, z}
\end{array}\right]^{T}=N V M_{z}\left[\begin{array}{lll}
\frac{\partial B_{x}}{\partial z} & \frac{\partial B_{y}}{\partial z} & \frac{\partial B_{z}}{\partial z}
\end{array}\right]^{T} .
$$

For our experiments only gradients across the $\mathrm{x}$-axis were used $\left(\mathrm{g}_{\mathrm{x}}\right)$. We can therefore reduce our mathematical model to two dimensions and simplify Eq. 14. An additional scalar needs to be added to account for the fact that imaging gradients can only be switched on for short times at high amplitudes and are therefore operated in an on/off fashion, referred to as the systems duty cycle $\left(D_{c}\right)$. Using that and Equations $5 \mathrm{~b}$ we can write the magnetic force along the $\mathrm{x}$-direction as:

$$
F_{m, x}=N V D_{c} M_{s} \frac{\partial B_{Z}}{\partial x} .
$$

The magnetic force is opposed by the drag force of the fluid which can be stated as Stokes drag force for low Reynolds numbers:

$$
F_{d}=-6 \pi \eta R_{c}\left(v_{c}-v_{f}\right) \text {, }
$$

where $R_{c}$ is the cell radius, $\eta$ the dynamic viscosity and $v_{c}-v_{f}$ is the difference between the cell velocity and the fluid velocity.

Cells are likely to aggregate in chain like structures. We can introduce a form factor $K_{n}$ to extend Stokes drag to non spherical objects[20]:

$$
\begin{aligned}
& F_{d}=-3 \pi \eta d_{n}\left(v_{c}-v_{f}\right) K_{n}, \text { and } \\
& K_{n}=\left[\frac{1}{3}+\frac{2}{3} \frac{d_{s}}{d_{n}}\right] .
\end{aligned}
$$

where $d_{n}$ is the diameter of a sphere with the same projected area as the area of the object projected normal to its direction of motion while $d_{s}$ is the diameter of a sphere with the same total surface area as the object. For a prolate spheroid Equation 18 can be written as:

$$
K_{n}=\left[\frac{1}{3}+\frac{2}{3} \frac{a^{2}+\frac{a c}{e} \sin ^{-1} e}{2 a c}\right] \text { and } e=\sqrt{1-\frac{a^{2}}{c^{2}}}
$$

where $a$ is the equatorial radius and $c$ the polar radius of a prolate spheroid $(a<c)$ as shown in Figure 1. We can use Eq. 17 to investigate the effect of cells arranged to prolate spheroids with different diameter to length ratios $l_{r}$ on targeting efficiency:

$$
l_{r} \equiv \frac{c}{a} \text {. }
$$


As the flow rates used for our experiments are all in the laminar flow region, the inflow profile can be described as:

$$
v_{f}(x)=2 \overline{v_{f}}\left[1-\left(\frac{x}{R_{t}}\right)^{2}\right]
$$

with $R_{t}$ as the tube radius and $\frac{J}{v_{f}}$ the average fluid velocity in the tube. The trajectory of cells can be calculated by equating the magnetic and the drag force (see Figure 1). Note that as our model does not include inertial forces, the cells will immediately travel at the maximum velocity determined by the magnetic and drag forces

$$
F_{m}+F_{d}=0 \text {. }
$$

The cell velocity in the z-direction is determined by the fluid velocity, as there is no magnetic force acting in the z-direction. Therefore the solution for the particle trajectory along the $\mathrm{x}$-axis will be independent of the solution for $\mathrm{z}$. The substitution of Equations 15 and 17 into Equation 22 for $\mathrm{x}$ leads to:

$$
\frac{d x}{d t}=\frac{N V D_{c} M_{s} \frac{\partial B_{Z}}{\partial x}}{3 \pi \eta d_{n} K_{n}} .
$$

The velocity along the z-axis is given by Eq. 21 . However as the cell changes its position along the $\mathrm{x}$ axis the velocity changes we therefore have to take the position along $\mathrm{x}$ over time into account which leads to:

$$
\frac{d z}{d t}=2 \overline{v_{f}}\left[1-\left(\frac{x(t)}{R_{t}}\right)^{2}\right] .
$$

Equations 23 and 24 lead to:

$$
x(t)=x_{0}+v_{c} t
$$

The velocity of cells due to the magnetic force is given as $v_{c}$ :

$$
v_{c}=\frac{N V D_{c} M_{s} \frac{\partial B_{Z}}{\partial x}}{3 \pi \eta d_{n} K_{n}}
$$

and the position along $\mathrm{z}$ as a function of time as:

$$
z(t)=2 t \overline{v_{f}}-\frac{2 t^{3} v_{c}^{2} \overline{v_{f}}}{3 R_{t}^{2}}-\frac{2 t^{2} v_{c} \overline{v_{f}} x_{0}}{R_{t}^{2}}-\frac{2 t \overline{v_{f}} x_{0}^{2}}{R_{t}^{2}} .
$$

In order to calculate the targeting efficiency, the initial distribution of cells in the tube at the start of the separation length $(\mathrm{z}=0)$ needs to be taken into account. It is assumed that the cells are randomly distributed over the circular tube cross-section. If this distribution is projected into the plane we derive:

$$
W(x)=2 R_{t} \sin \left(\cos ^{-1} \frac{x}{R_{t}}\right),
$$

where $W$ is a weighting factor for the cell number distribution at the start of the separation area (see Supplementary Figure 1). The trajectories for cells can be calculated using Eqs. 25 and 27 (see Supplementary Figure 2). If they are weighted with Eq. 28 the distribution at the start and end of the separation distance can also be calculated.

It is assumed that cells which are above or below the z-axis at the end of the separation length $z_{0}$ (see Figure 1) will end up in their corresponding exit tubes. The targeting efficiency can hence be defined at that point as follows:

$$
T_{e}=2 *\left(\frac{N_{\text {target tube }}}{N_{\text {total }}}-0.5\right),
$$

where $N_{\text {target tube }}$ is the number of cells at the end of the tube to which the cells were targeted to and $N_{\text {total }}$ is the total amount of cells in both tubes. The subtraction of 0.5 is accounting for the distribution without any steering gradients present, which is 0.5 for both exit tubes.

\section{3 Estimating parameters to achieve a given targeting efficiency}

In order to estimate how much iron oxide needs to be internalised per cells to achieve a certain steering efficiency Eq. 28 needs to be integrated. For a selected targeting efficiency $T_{e}$, the fraction of $N_{e}=\frac{N_{\text {target tube }}}{N_{\text {total }}}$ cells have to end up in the targeted tube. We therefore integrate Eq. 28 from $-R_{t}$ to $x_{t e}$ if the magnetic force points along the positive $\mathrm{x}$-axis. In this case $x_{t e}$ indicates the position along 
the x-axis for which the integral between it and $R_{t}$ accounts for $T_{e}$ of all cells. We can solve the following equation for $x_{t e}$ :

$$
N_{e} R_{t}^{2} \pi=R_{t}\left(x_{t e} \sqrt{1-\frac{x_{t e}^{2}}{R_{t}^{2}}}+R_{t} \sin ^{-1} \frac{x_{t e}}{R_{t}}\right)+\frac{R_{t}^{2} \pi}{2} .
$$

If we chose $T_{e}$ to be 0.9 , than form Eq. 28 it follows that $N_{e}$ has to be 0.95 .

In order to achieve the 0.9 targeting efficiency, a cell starting at $x_{t e}$ and $\mathrm{z}=0$ has to reach $x=0$ at the end of the separation length $z_{0}$. Equation 27 and 25 can be solved for $t$ :

$$
t=\frac{3 R_{t}^{2} z_{0}}{2 \overline{v_{f}}\left(3 R_{t}^{2}-x_{t e}^{2}\right)} .
$$

From Equations 30 and 25, $N_{p}$ can be calculated as well as the field gradient strength or duty cycle necessary to reach a given steering efficiency. For parameters used in the model see Table 1. 


\section{Materials and Methods}

Cell-steering experiments were conducted with different flow rates, cell concentrations and fluid viscosities to investigate their effects on targeting efficiency. Additionally, confocal endoscopy was performed to investigate parameters used in our model (section 2) describing cell aggregation.

\subsection{MRT of labelled cells}

A vascular bifurcation model consisting of a cylindrical tube with an internal diameter of $0.8 \mathrm{~mm}$ and a $30^{\circ}$ bifurcation (see Figure 1) was placed into the isocentre of a 9.4T MRI scanner (VNMRS, Varian Inc. Palo Alto, CA) equipped with a $60 \mathrm{~mm}$ bore size gradient set (rise time $5 \mathrm{~T} \mathrm{~m}^{-1} \mathrm{~ms}^{-1}$, max. gradient strength $1 \mathrm{~T} / \mathrm{m}$ ) and connected to an infusion pump (PHP2000 Harvard Instruments, UK). Labelled cells (see Appendix A) suspended in PBS containing 3\% foetal bovine serum (FBS) (or 50\% FBS) where flushed through the flow phantom infused at flow rates of $0.06 \mathrm{~mL} / \mathrm{min}$ to $2.5 \mathrm{~mL} / \mathrm{min}$, leading to a mean velocity of $0.2 \mathrm{~cm} / \mathrm{s}$ to $8 \mathrm{~cm} / \mathrm{s}$ assuming parabolic laminar flow. During the infusion, gradients (amplitude + or $-500 \mathrm{mT} / \mathrm{m}$ ) were applied in the x-direction, perpendicular to the direction of flow (see Figure1). Due to hardware capabilities the gradients were pulsed ( $2 \mathrm{~ms}$ on, $7 \mathrm{~ms}$ off using max. slew rate). Cell suspensions leaving each bifurcation outlet tube were collected and cell concentrations were estimated using a haemocytometer. This was repeated three times for each gradient direction and fluid velocity.

\subsection{Confocal endoscopy}

The Cellvizio (Mauna Kea Technologies, Paris, France), a fibered confocal microscope, was used for the acquisition of dynamic microscopic in vitro images of the fluorescent cells. An MR compatible (7 metre long) 600 micron diameter microprobe, comprising approximately 10,000 coherent optical fibres was scanned fibre by fibre via the MKT laser scanning unit behaving as the confocal pinhole and objective lens of a conventional near real-time confocal microscope for remote acquisitions at 12 frames per second. The MR-compatible ProFlex S-microprobe was used which provided an image resolution of approximately $4 \mu \mathrm{m}$ and a circular field of view with a diameter of $500 \mu \mathrm{m}$. The end of the optical fibre was placed into the middle of the inflow channel of the flow phantom where a hole was drilled to connect it to the fluid (see Figure 1 and 3). The laser scanning unit emitted a laser beam at an excitation wavelength of $488 \mathrm{~nm}$ and collected the fluorescence signal in a bandwidth of $500 \mathrm{~nm}$ to $650 \mathrm{~nm}$. Finally, ImageCell Software allowed for real-time visualisation of the microscopic images and for manual settings of the contrast. 


\section{Results and discussion}

In the following sections we compare our experimental results with model predictions and assess some of the assumptions used in the model, in particular with regard to cell aggregation. Experimental variation of some of these parameters and their effect on targeting efficiency will also be discussed.

\subsection{Theoretical prediction for single cells and aggregates}

Figure 2A shows a comparison between experimental results and theoretical predictions for two different cell concentrations, together with the theoretical prediction without cell aggregation. This figure demonstrates that the theoretical prediction for single cells differs significantly from experimental results, indicating that aggregation could play an important role, which may explain the discrepancy with the experimental data. When cell aggregation was assumed, cells were modelled as prolate spheroids with a polar to equatorial diameter ratio of $l_{r}=5$. Cell aggregation and aggregate shape were included in our model via Equations 15 and 18. The number of cells $\mathrm{N}$ in such an aggregate was derived via fitting the experimental data to the model while the diameter length ratio was estimated from confocal endoscopy data. For $\mathrm{N}$ with the range 60 to 80 coefficients of determination $\left(\mathrm{R}^{2}\right)$ were found to be between 0.93 and 0.97 , showing a good agreement between the model and experimental data.

It should be stated that the numerical validity of the results is dependent on the validity of the model assumptions of no gravitational and inertial effects. Neither gravity nor inertia are likely to have a significant effect on our predictions, as sedimentation is slow and the cells pass through the flow phantom within a few seconds. Inertia is neglectable for small cells, especially when the magnetic force is applied for the entire time a cell spends in the flow phantom. The assumption of a random distribution for cells entering the separation area is harder to assess as a long tube is used to connect the phantom with the syringe pump. However, applying gradients along the positive or negative $\mathrm{x}$-axis lead to similar results indicating no initial bias. Finally the assumption of a laminar parabolic flow profile is justified for the fluid viscosities and flow rates used in our experiments.

\subsection{Effect of viscosity and cell concentration}

Subsequently we investigated two different cell concentrations to assess if doubling the cell concentration leads to increased cell aggregation and hence increased steering efficiency. This was observed, however the effect was relatively small. The model used a constant aggregate size which is likely to be incorrect particularly for higher flow rates where increased shear forces overcome magnetic dipole interactions and hence aggregation (see confocal results below). We therefore see a discrepancy between the model and experimental data starting between 5 and $6 \mathrm{~cm} / \mathrm{s}$ for $2 \times 10^{6} \mathrm{cells} / \mathrm{ml}$ and 6 and $8 \mathrm{~cm} / \mathrm{s}$ for $4 \times 10^{6}$ cells $/ \mathrm{ml}$. Figure 2B shows experimental results and theoretical predictions for two different fluid viscosities. The increases in fluid viscosity lead to a modest decrease in targeting efficiency. Changing the fluid viscosity does affect the drag force which needs to be overcome and to a lesser degree cell aggregation.

This can be seen in figure 2B for which the aggregate size was kept at 60 cells with a diameter to length ratio of 5 and measured fluid viscosities were used to calculate theoretical targeting efficiencies. These predictions fit the experimental data assuming that the aggregate size does not change significantly. The importance of magnetic dipole interactions for targeting applications have been described previously [21-23]. Also there have been previous publications where a similar bifurcation has been modelled but in the context of permanent magnets and without cell aggregation $[24,25]$. However, in comparison to these studies we used cells with internalised particles and not magnetic particles alone. This changes aggregation behaviour as particles are kept at greater distances due to other cellular compartments and their membranes, while aggregated cells might stick together more readily depending on the cell line used. Forces which oppose aggregation of particles are electrostatic and van der Waals forces. These forces have a shorter range compared to magnetic dipole interactions and are shielded to a large extend by the cells. We should therefore expect slight differences between the aggregation behaviour of ferrofluids and cells even if the same iron concentration per unit suspension volume is used.

\subsection{Assessment of aggregation using confocal endoscopy}


In order to investigate cell aggregation in the context of MRT we used a confocal endoscope. This system operates as a conventional confocal microscope as the coherent fibre bundle is rapidly scanned point by point, conducting light to and from the sample, acting as both the objective lens and the confocal pinhole. Figure 3 shows single frames from videos taken at different fluid velocities without a magnetic field present and with a homogenous magnetic field of 9.4T (bore of the MRI scanner) (see supplementary movie S1-S6). For fluid velocities of $1 \mathrm{~cm} / \mathrm{s}$ and $2 \mathrm{~cm} / \mathrm{s}$ (Figure 3A and B) cells travelled as aggregates in the magnetic field of the MRI scanner; these aggregates showed roughly elongated shapes containing between $20-80$ cells. We estimated the diameter to length ratio of these aggregates to be around 5. For the same experiments conducted without a magnetic field (outside of the MRI scanner), no cell aggregation was observed. When the fluid velocity was increased to $4 \mathrm{~cm} / \mathrm{s}$ (Figure3C) cells did not form large aggregates but rather chain-like aggregates with 2 to 10 cells arranged into a chain. The transition between large aggregates (several 10s of cells) and smaller chain like aggregates was observed at a fluid velocity of approximately $3 \mathrm{~cm} / \mathrm{s}$. It has to be accepted that the imaging fibre was introduce into the flow phantom (see Figure 3D) and may have caused some minor flow disturbances.

Mathieu et al. [23] showed that the average chain length of iron oxide particles without fluid flow at a concentration of $0.6 \mathrm{mg} / \mathrm{ml}$ and $0.4 \mathrm{~T}$ was about $31 \mu \mathrm{m}$ and for $1.13 \mathrm{mg} / \mathrm{ml}$ at a flow rate of < $1.2 \mathrm{~cm} / \mathrm{s}$ in an $1.5 \mathrm{~T}$ MRI scanner approximately $650 \mu \mathrm{m}$. In our study, we reached an iron concentration, per unit suspension volume, of approximately $0.5 \mathrm{mg} / \mathrm{ml}$ in labelled cells and observe aggregates with a length of $150-250 \mu \mathrm{m}$ (see S2). This difference could be attributed to the internalisation of particles by cells and the difference in fluid velocity, which may increase aggregation. We also observed that, cells with internalised particles showed a different aggregation behaviour at lower flow rates while aggregation at higher flow rates follows a similar (chain) pattern as observed for ferrofluids. The aggregation behaviour observed for low flow rates might, in part, be caused by the strong field gradients at the bore of the magnet. These gradients will induce transverse motion which will increase the likelihood for aggregation as cells will come close enough to other cells to experience their magnetic dipole moment.

Cell aggregation is clearly an important factor for targeting of cells using MRT and will always be present unless cells are very dilute and or contain only a very low amount of iron oxide. The higher magnetophoretic velocity of aggregates allows for increased targeting efficiency at higher flow rates. This can be further enhanced by increasing the cell concentration in the injection solution. However, if small vessels are to be targeted, large aggregates might perturb blood flow leading to vessel occlusion. Although shear forces will increase in small capillaries, it is not certain if these forces will be big enough to disaggregate cells. However, the nanoparticles used for these experiments are super paramagnetic and the removal of the subject from the strong field of the MRI scanner would lead to the decay of dipole interactions and thus the cells should be able to disperse. This should also be the case for ferrofluids. However, there is an additional risk that during the contact time between cells, some may have bound together too strongly to be dispersed by the fluid flow. This is of particular relevance for MRT, but it will also be of importance for magnetic targeting applications that use permanent or electro magnets. Further research will be needed to address this question.

\subsection{Investigation of MRT using confocal endoscopy}

In order to study the effect of the imaging gradients applied to target cells we applied a gradient amplitude of $300 \mathrm{mT} / \mathrm{m}$ with a duty cycle of $2 / 7$ perpendicular to the orientation of the fluid flow (using a gradient coil with a larger inner diameter then used for the other experiments). The supplementary movie 7 shows the effect of the gradients on the direction vector of the cells. For the case with and without gradients, 15 cells were selected at random and tracked until they left the field of view. Without any gradients applied, the direction vector for cells was $70 \pm 13^{\circ}$ while the application of the gradients changed it to $25 \pm 14^{\circ}$. However we were not able to study the effect of the gradients on cell movement at lower flow rates as large aggregates rapidly blocked the field of view (cells tended to stick to the glass surface of the endoscope tip).

\subsection{The influence of other parameters on targeting efficiency}

Our mathematical model permits the investigation of the effects of different parameters on targeting efficiency (see section 2.3). Figure 4A for example shows the volume fraction that iron oxide particles would need to take up in a cell to reach a targeting efficiency of $90 \%$ for different gradient amplitudes. 
For this plot no cell aggregation was assumed. It can be seen that such a high targeting efficiency is hard to achieve. Admittedly cell aggregation will lead to higher targeting efficiency at lower flow rates, but achieving high targeting efficiency at higher flow rates will be difficult. High targeting efficiencies will be important when MRT is used at several subsequent bifurcations to guide a bolus of cells to a target location. In order to reach the needed targeting efficiencies further optimisation will be necessary. It is clear that several factors can be influenced to maximise targeting efficiency such as: the saturation magnetisation of the superparamagnetic particles, amount of particles internalised in cells, cell concentration in bolus, viscosity, gradient amplitude and the duty cycle. The saturation magnetisation for the particles used can only be improved slightly. Different particles could be used e.g. iron cobalt nanoparticles with a high saturation magnetisation. Most of these particles are not biodegradable, limiting their potential applicability. Increasing the amount of internalised particles would be difficult as our cells are already strongly labelled and such labelling efficiencies are hard to achieve for cells with no or low phagocytic activity. The cell concentrations used in our experiments are not particularly high and can be increased easily, but the potential risk of blocking smaller vessels needs to be addressed. A lower limit for the viscosity will be given by the viscosity of an isotonic saline solution while its upper limit will be the viscosity of blood. Gradient amplitude and duty cycle can be improved via improved hardware e.g. gradient inserts optimised for targeting applications. The limit for such gradients will be cooling capacity and the maximum switching rate that does not lead to peripheral nerve stimulation.

Figure 4B shows the effect of the aggregate geometry on the targeting efficiency. As the magnetic force is a volumetric force and the drag force is dependent on the projection surface in flow direction, the deviation from a spherical object to an elongated one reduces the targeting efficiency. From the analysis of our videos we observed that the equatorial to polar diameter ratio is approximately five. If 40 cells in one spherical aggregate are necessary to explain the experimental results shown by the blue line in Figure 2A, the number of cells in one aggregate with a diameter to length ratio of 5 will increase to 60 . The diameter to length ratio of aggregates is dependent on the polydispersity of the solution. It might therefore be possible to add a small concentration of ferrofluid to increase the size of these aggregates and reduce their diameter to length ratio.

\subsection{Considerations for active control of cell delivery}

In order to implement an active control strategy for cell delivery on a MRI scanner three steps are necessary. Firstly the current position of cells needs to be determined. Secondly the necessary gradient strength to bring them to the desired location needs to be calculated, and thirdly this gradient needs to be applied. This sequence of steps has to be repeated very rapidly to guide the cells through the vascular network as they are carried along by the blood flow. An analytical model is advantageous for the implementation of a control strategy, as calculations can be performed very rapidly. We have shown that a simple analytical model can be derived which could be used for such an application. However, the fast detection of a bolus of labelled cells in blood vessel will be challenging as the concentration of iron per millilitre of that bolus will be a few milligrams at best. The feasibility for the active guidance of a steel ball in a carotid artery of a swine has been shown previously by Martel et al [15]. The control strategy used relied on a pre-planned path on which the steel ball was kept using a feedback control loop which determined the difference between actual position and pre-planned position. Steering cells will be more difficult as they are not a single rigid object. An active control strategy which relies on a predictive estimate for the path cells follow could be used. This is possible with fast algebraic methods and might be useful to increase steering efficiency. 


\section{Conclusions}

We have presented a simple analytical model which describes the steering efficiency of magnetically labelled cells inside of a small bifurcation in the context of MRT. Such a model could be used for the implementation of an active control strategy for cell delivery using MRT. This model takes cell aggregation into account and models these aggregates as prolate spheroids. Predicted targeting efficiencies agree with experimental results when cell aggregation is taken into account, highlighting the importance of cell aggregation in this context. We have shown that changing the cell concentration or fluid viscosity in our model and experimental setup lead to the expected behaviour. We show that different parameters affecting targeting efficiency can be studied theoretically. In addition we confirmed the expected aggregation inside the MRI scanner via confocal endoscopy. Confocal endoscopy showed aggregate sizes at lower flow rates which are in the predicted range of our theoretical model. We found a transition from large aggregates containing up to 100 cells to small chain like aggregates with up to 10 cells at flow rates of $4-6 \mathrm{~cm} / \mathrm{s}$ in this model. The application of imaging gradients to move cells, leads to changes of the direction vectors of cells which could be observed using near real-time confocal micro-endoscopy. 


\section{Acknowledgment}

The authors would like to acknowledge Carmin Habalsa (UCL) for hMNCs and Dr. Rory Warner and Dr Dan Green (Agilent Technologies, Oxford) for field maps, Prof. Roger Ordidge (UCL Biophysics) and Prof. David Hawkes (UCL CMIC) for their helpful discussions.

In addition we would like to thank the British Heart Foundation, the Engineering and Physical Sciences Research Council, Guys \& St Thomas' Charity, The Biological Sciences Research Council, Department of Health (DOH) UK DLH Clinician Scientist Award to Dr. Cook and GSTFT/KCL Comprehensive Biomedical Research Centre for supporting this study. 


\section{Appendix A: Cell preparation}

Human mononuclear cells were collected by leukapheresis from peripheral blood of G-CSF-stimulated donors. Cells were washed twice with PBS, centrifuged for $10 \mathrm{~min}$ at $400 \mathrm{~g}$, plated in Dulbecco's Modified Eagle Medium (DMEM) (Gibco, UK) and incubated at $37{ }^{\circ} \mathrm{C}$ and $5 \% \mathrm{CO}_{2}$ for 2 hours. After two hours non-adherent cells were washed away and the media replaced with fresh DMEM $+10 \%$ fetal bovine serum (FBS) (Invitrogen, UK). Cell labelling was performed at $>80 \%$ confluency by adding $50 \mu \mathrm{L}$ BioMag Goat anti-Rabbit IgG particles solution (Bangs Laboratories Inc, IN, USA) (particles washed 3 times with fresh media) and incubation of cells for 24 hours. After the incubation period cells were washed three times with PBS without detaching the cells. Cells were incubated with DMEM containing $25 \mu \mathrm{M}$ CellTracker Green CMFDA (5-chloromethylfluorescein diacetate) (Invitrogen, Paisley, UK) were added and cells incubated for 30 minutes. Following that, cells were detached using PBS containing $5 \mathrm{mmol} / \mathrm{l}$ EDTA (ethylenediaminetetraacetic acid) for 10 minutes and then flushed from the surface and washed twice with PBS (by centrifugation at $300 \mathrm{~g}$ for 5 minutes). The labelling with the fluorescent dye was only used for experiments which included confocal endoscopy. Cells were re-suspended to $2 \times 10^{6}$ and $4 \times 10^{6}$ cell/ml in PBS containing $3 \%$ FBS or to $2 \times 10^{6}$ cells $/ \mathrm{ml}$ in PBS containing 50\% FBS.

\section{Supporting Material}

Videos corresponding to Figure 3:

S1: no magnetic field, flow rate: $1 \mathrm{~cm} / \mathrm{s}$

S2: homogeneous field, flow rate: $1 \mathrm{~cm} / \mathrm{s}$

S3: no magnetic field, flow rate: $2 \mathrm{~cm} / \mathrm{s}$

S4: homogeneous field, flow rate: $2 \mathrm{~cm} / \mathrm{s}$

S5: no magnetic field, flow rate: $4 \mathrm{~cm} / \mathrm{s}$

S6: homogeneous field, flow rate: $4 \mathrm{~cm} / \mathrm{s}$

The effect of the gradients on cell movement:

S7: homogeneous field, flow rate: $3 \mathrm{~cm} / \mathrm{s}$, field gradient turned on and off

Supplementary figures:

S8: Supplementary figures 1 and 2 


\section{References}

[1] Nakajima J, Murakawa T, Fukami T, Goto S, Kaneko T, Yoshida Y, Takamoto S and Kakimi K 2010 A phase I study of adoptive immunotherapy for recurrent non-small-cell lung cancer patients with autologous gammadelta T cells Eur. J. Cardiothorac. Surg. 37 1191-7

[2] Geron Corporation 2009 World's first clinical trial of human embryonic stem cell therapy cleared Regen. Med. 4161

[3] Brinkman D M, de Kleer I M, ten Cate R, van Rossum M A, Bekkering W P, Fasth A, van Tol M J, Kuis W, Wulffraat N M and Vossen JM 2007 Autologous stem cell transplantation in children with severe progressive systemic or polyarticular juvenile idiopathic arthritis: Longterm followup of a prospective clinical trial Arthritis Rheum. 56 2410-21

[4] Snowden J A, Martin R and Watt S M 2009 Clinical stem cell therapies for severe autoimmune diseases Transfus. Med. 19 223-34

[5] Yeo C and Mathur A 2009 Autologous bone marrow-derived stem cells for ischemic heart failure: REGENERATE-IHD trial Regen. Med. 4 119-27

[6] Yerebakan C, Kaminski A, Westphal B, Liebold A and Steinhoff G 2008 Autologous bone marrow stem cell therapy for the ischemic myocardium during coronary artery bypass grafting Minim. Invasive Ther. and Allied Technol. 17 143-8

[7] Wollert K C et al 2004 Intracoronary autologous bone-marrow cell transfer after myocardial infarction: the BOOST randomised controlled clinical trial Lancet 364 141-8

[8] Tang X L et al 2010 Intracoronary administration of cardiac progenitor cells alleviates left ventricular dysfunction in rats with a 30-day-old infarction Circulation 121 293-305

[9] Pankhurst Q A, Connolly J, Jones S K and Dobson J 2003 Applications of magnetic nanoparticles in biomedicine J. Phys. D Appl. Phys. 36 167-181

[10] Chen H, Kaminski M D, Pytel P, Macdonald L and Rosengart A J 2008 Capture of magnetic carriers within large arteries using external magnetic fields J. Drug Target. 16 262-8

[11] Kim D H, Kim K N, Kim K M and Lee Y K 2009 Targeting to carcinoma cells with chitosanand starch-coated magnetic nanoparticles for magnetic hyperthermia J. Biomed. Mater. Res. A $\mathbf{8 8} 1-11$

[12] Hofmann A et al 2009 Combined targeting of lentiviral vectors and positioning of transduced cells by magnetic nanoparticles Proc. Natl. Acad. Sci. U S A 106 44-9

[13] Kyrtatos P G, Lehtolainen P, Junemann-Ramirez M, Garcia-Prieto A, Price A N, Martin J F, Gadian D G, Pankhurst Q A and Lythgoe M F 2009 Magnetic tagging increases delivery of circulating progenitors in vascular injury JACC Cardiovasc. Interv. 2 794-802

[14] Lübbe A S, Bergemann C, Brock J and McClure D G 1999 Physiological aspects in magnetic drug-targeting J. Magn. Magn. Mater. 194 149-55

[15] Martel S et al 2007 Automatic navigation of an untethered device in the artery of a living animal using a conventional clinical magnetic resonance imaging system Appl. Phys. Lett. 90 $114105-3$ 
[16] Martel S, Felfoul O, Mohammadi M and Mathieu J B 2008 Interventional procedure based on nanorobots propelled and steered by flagellated magnetotactic bacteria for direct targeting of tumors in the human body Conf. Proc. IEEE Eng. Med. Biol. Soc. 2497-500

[17] Mathieu J B and Martel S 2003 MRI System as a mean of propulsion for a microdevice in blood vessels Conf. Proc. IEEE Eng. Med. Biol. Soc. 3419-22

[18] Riegler J, Wells J A, Kyrtatos P G, Price A N, Pankhurst Q A and Lythgoe M F 2010 Targeted magnetic delivery and tracking of cells using a magnetic resonance imaging system Biomaterials 31 5366-71

[19] Han B H, Park S and Lee S Y 2008 Gradient waveform synthesis for magnetic propulsion using MRI gradient coils Phys. Med. Biol. 53 4639-49

[20] Leith D 1987 Drag on Nonspherical Objects Aerosol Sci. Technol. 6 153-61

[21] Cregg P J, Murphy K and Mardinoglu A 2009 Inclusion of magnetic dipole-dipole and hydrodynamic interactions in implant-assisted magnetic drug targeting J. Magn. Magn. Mater. 321 3893-8

[22] Erica M C, Peter G M and John K E 2010 Particle size, magnetic field, and blood velocity effects on particle retention in magnetic drug targeting Med. Phys. 37 175-82

[23] Mathieu J B and Martel S 2009 Aggregation of magnetic microparticles in the context of targeted therapies actuated by a magnetic resonance imaging system J. Appl. Phys. 106 044904-7

[24] Mohanty S, Baier T and Schönfeld F 2010 Three-dimensional CFD modelling of a continuous immunomagnetophoretic cell capture in BioMEMs Biochem. Eng. J. 51 110-16

[25] Takeda S I, Mishima F, Terazono B, Izumi Y and Nishijima S 2006 Development of magnetic force-assisted gene transfer system using biopolymer-coated ferromagnetic nanoparticles $S c i$. Technol. Adv. Mater. 7 308-14 
Table 1: Model parameters

\begin{tabular}{|lccc|}
\hline Variable & Symbol & Value & Units \\
\hline magnetic induction & $B_{0}$ & 9.4 & $\mathrm{~T}$ \\
gradient strength & $g_{x}$ & $0.5(0.5-10)$ & $\mathrm{T} \mathrm{m}^{-1}$ \\
saturation magnetisation & $M_{s}$ & 314000 & $\mathrm{~A} \mathrm{~m}^{-1}$ \\
number of particles per cell & $N$ & 250 & \\
tube radius & $R_{t}$ & 0.0004 & $\mathrm{~m}$ \\
cell radius & $R_{c}$ & 0.000005 & $\mathrm{~m}$ \\
average fluid velocity & $\bar{v}_{f}$ & $0.005-0.08$ & $\mathrm{~m} \mathrm{~s}^{-1}$ \\
separation length & $\mathrm{z}_{0}$ & 0.06 & $\mathrm{~m}$ \\
Duty cycle for steering gradients & $D_{c}$ & $2 / 7$ & \\
fluid viscosity & $\eta$ & $0.0016-0.0024$ & $\mathrm{~kg} \mathrm{~m}^{-1} \mathrm{~s}^{-1}$ \\
diameter length ratio & $l_{r}$ & 5 & \\
cells in one aggregate & & $1-80$ & \\
\hline
\end{tabular}




\section{Figure Legends}

\section{Figure 1:}

A shows a schematic drawing of the separation area of the vascular flow phantom. An aggregate of magnetically labelled cells is symbolised by grey circles and their path over time by the fading copies of this aggregate assuming a positive $\mathrm{X}$ gradient. A grey circle with a dashed line indicates the field of view of the confocal endoscope. $\mathrm{B}_{0}$ : orientation of the magnetic field in the MRI scanner, $\mathrm{F}_{\mathrm{m}}$ : magnetic force, $\mathrm{F}_{\mathrm{D}}$ : fluid drag force, $\mathrm{R}_{\mathrm{C}}$ : radius of cells, $\mathrm{R}_{\mathrm{t}}$ : radius of tube, $\mathrm{v}_{\mathrm{f}}$ : fluid velocity, $\mathrm{a}$ : equatorial radius of prolate spheroid as a model for aggregated cells, c: polar radius of prolate spheroid. B shows three dimensional plots for the magnetic field components $\left(B_{x}, B_{y}, B_{z}\right)$ in the MRI scanner without a magnetic field gradient while $\mathbf{C}$ shows plots for the magnetic field components in the MRI scanner with a field gradient of $550 \mathrm{mT} / \mathrm{m}$ applied along the $\mathrm{x}$-axis. (The same coordinate system as used for the model is used for the field plots.

\section{Figure 2:}

A: Comparison of experimental results versus theoretical prediction for targeting efficiency. The green dots show the experimental results for a cell concentration of $4 \times 10^{6}$ cells $/ \mathrm{ml}$ while the blue dots correspond to $2 \times 10^{6}$ cells $/ \mathrm{ml}$, vertical bars indicate the standard deviation. Theoretical predictions are shown as continuous lines; purple: no cell aggregation, blue: 60 cells aggregated with a prolate equatorial to polar diameter ratio of 5, green: 80 cells aggregated with the same diameter ratio.

B The effect of different fluid viscosities on targeting efficiency. Blue and red dots show experimental results for $\mathrm{PBS}+3 \%$ serum and $\mathrm{PBS}+50 \%$ serum. The continuous lines show the theoretical predictions for a viscosity of $0.0016 \mathrm{~Pa}$ and $0.0024 \mathrm{~Pa}$ s assuming no changes in aggregate size.

\section{Figure 3:}

Singe frame images from confocal endoscopy videos acquired at a frame rate of 12 images per second for different fluid velocities without a magnetic field and in an homogeneous magnetic field of 9.4T (inside the bore of an MRI scanner). The left column corresponds to no magnetic field while the right column corresponds to 9.4 T. A: flow rate of $1 \mathrm{~cm} / \mathrm{s}, \mathbf{B}: 2 \mathrm{~cm} / \mathrm{s}, \mathbf{C}: 4 \mathrm{~cm} / \mathrm{s}$. The scale bar in the lower right hand corner of each image indicates $50 \mu \mathrm{m}$ while the field of view is $500 \mu \mathrm{m}$ with a depth perception of about $100 \mu \mathrm{m}$. The arrow in the right column figure A indicates the orientation of the magnetic field for the whole right column. D shows a schematic drawing how the microprobe was introduced into the flow phantom and how chain like aggregates are aligned with the main field of the MRI scanner (B0). In the lower right hand corner chain like aggregates of cells are magnified by a factor or three $(3 \mathrm{X})$.

\section{Figure 4:}

A Predictions for the volume fraction on iron oxide in cells necessary to reach a given targeting efficiency without cell aggregation for different gradients strengths at a duty cycle of $50 \%$. gx: gradient strength $\mathrm{T} / \mathrm{m}$.

B The effect of different polar to equatorial diameter ratio on targeting efficiency assuming the total number of cells in an aggregate is constant. 
A

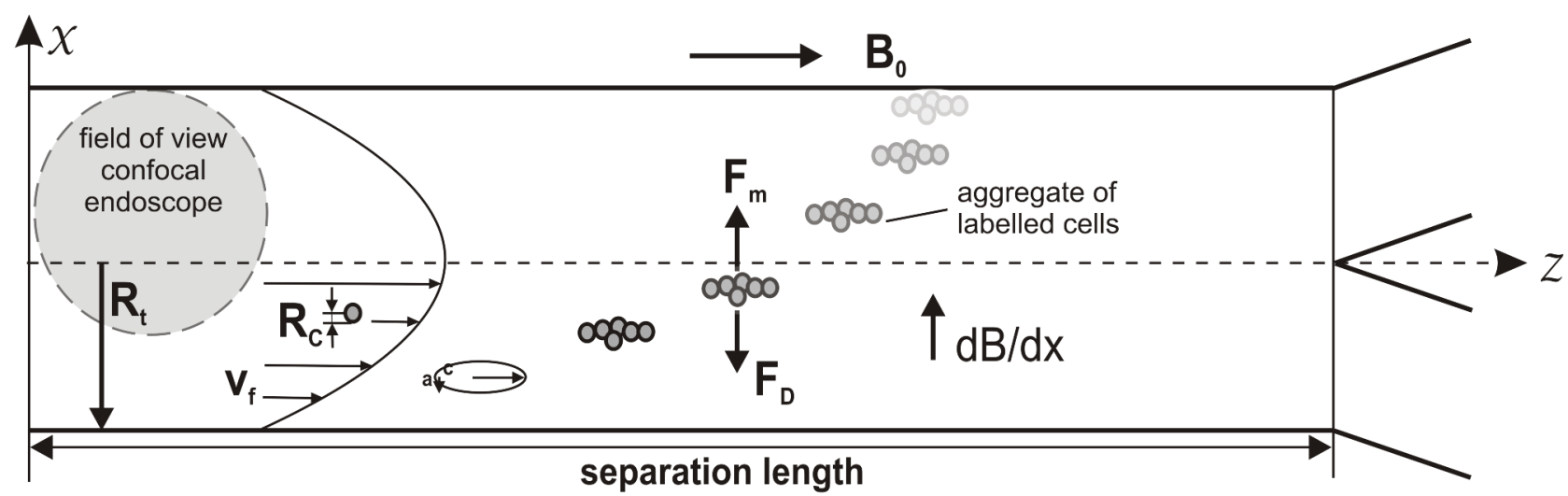

B
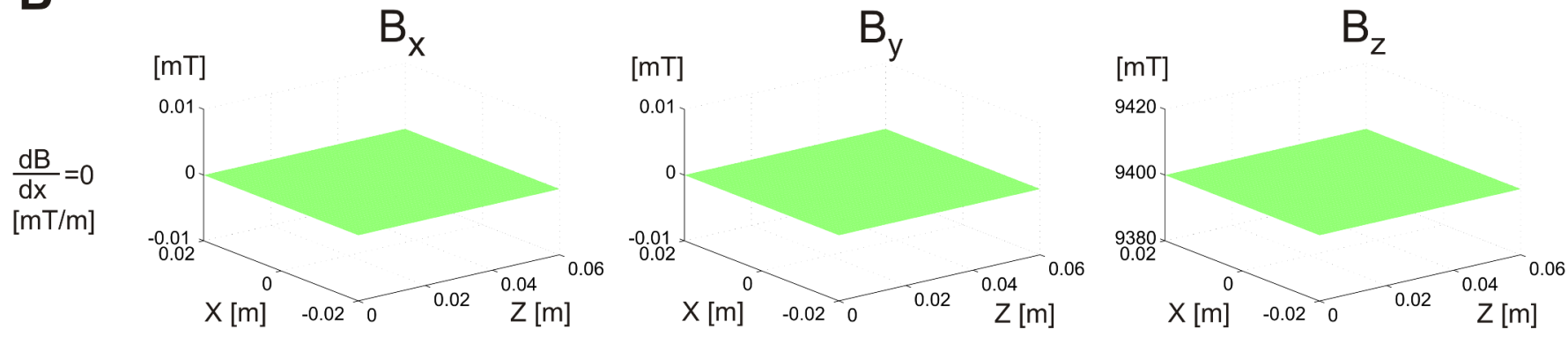

C
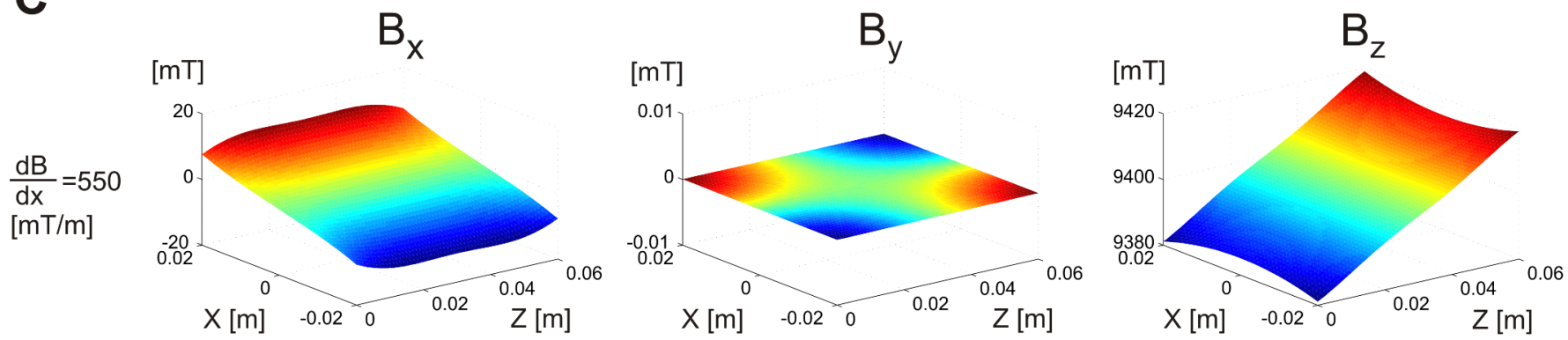

Figure 1 (figure1a_c_new.tif) 
A Targeting efficiency for different cell concentrations

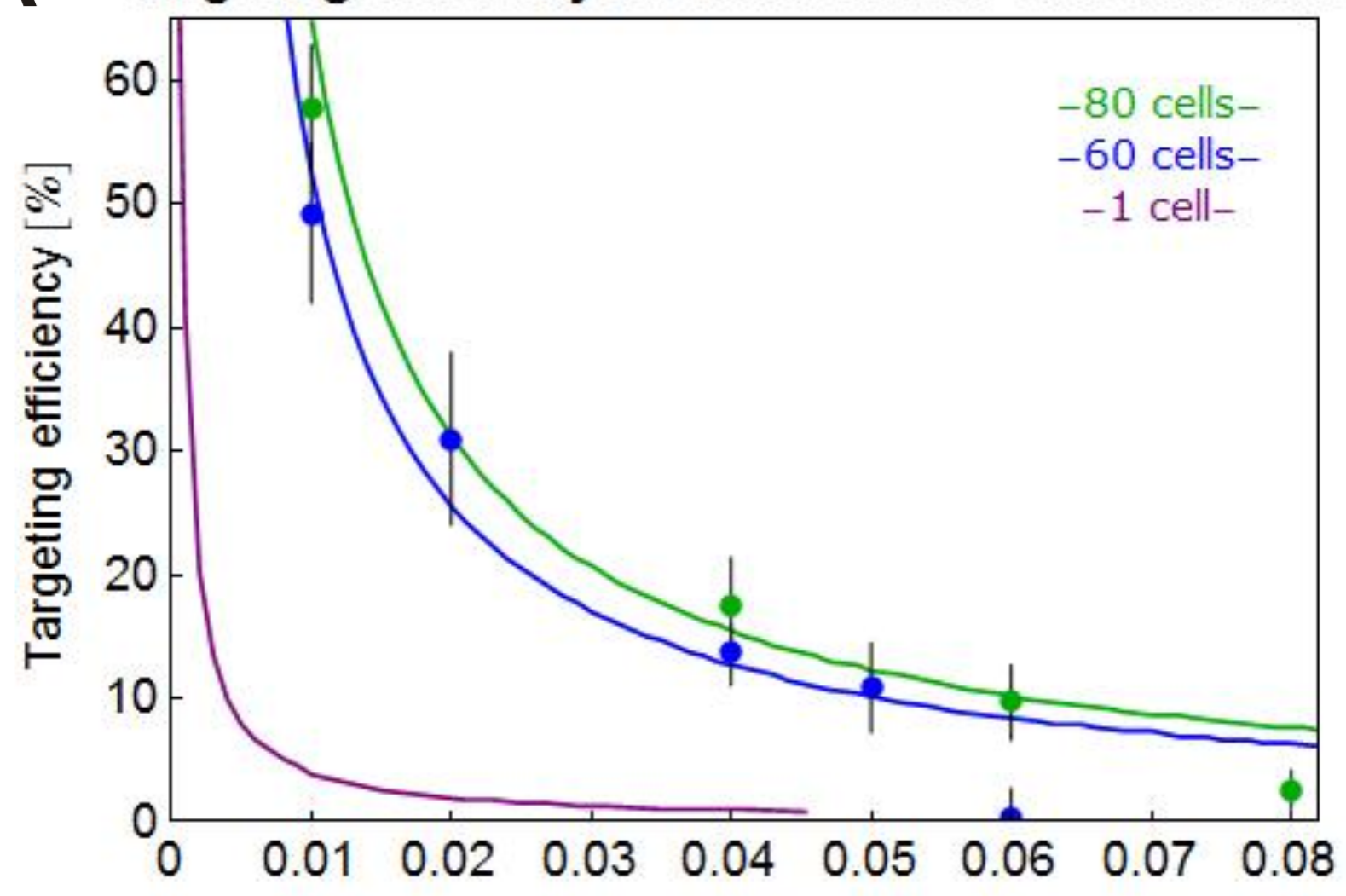

Fluid velocity $[\mathrm{m} / \mathrm{s}]$

B Targeting efficiency for different fluid viscosities

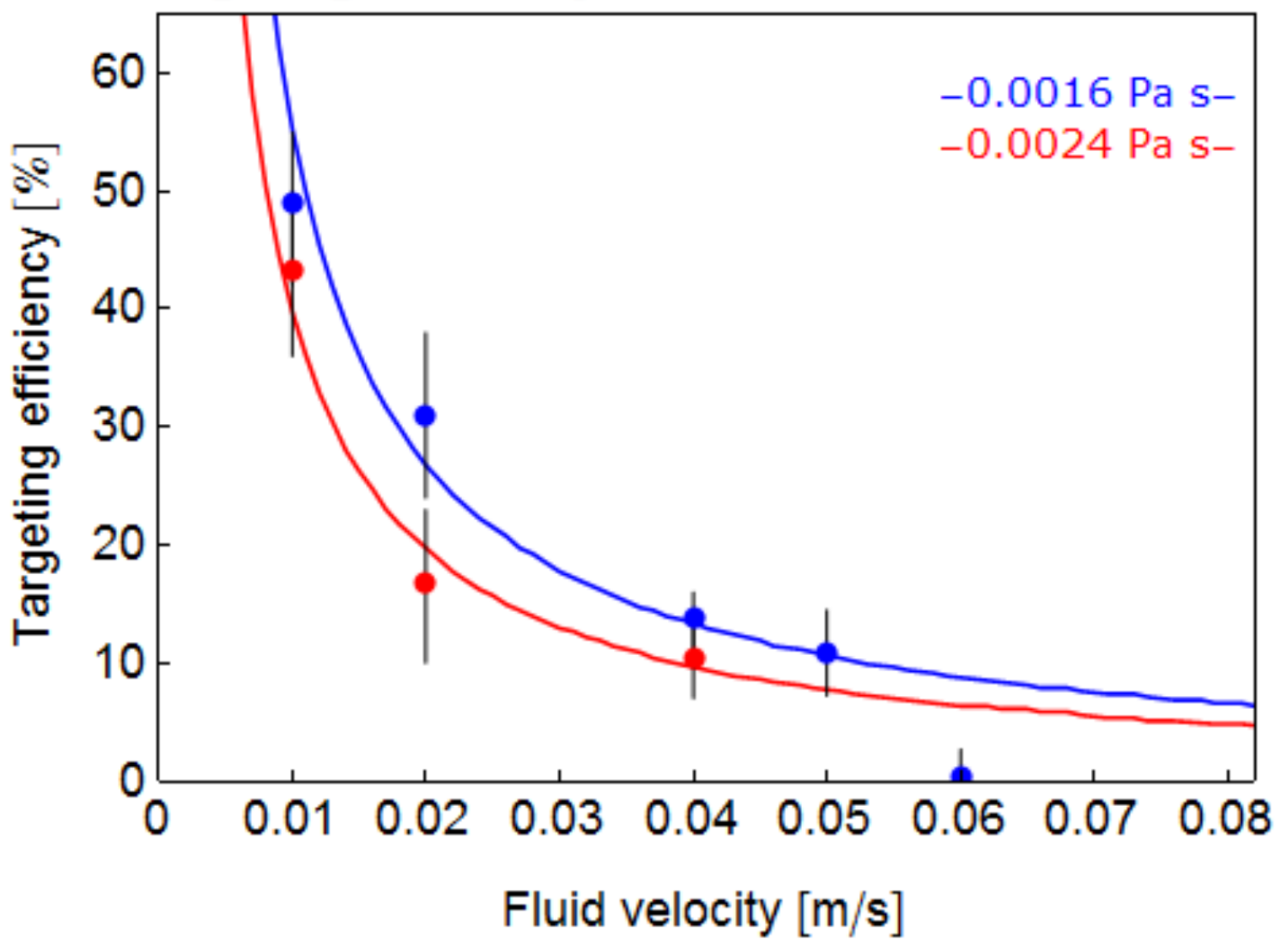

Figure 2 (figure2a_b.tif) 


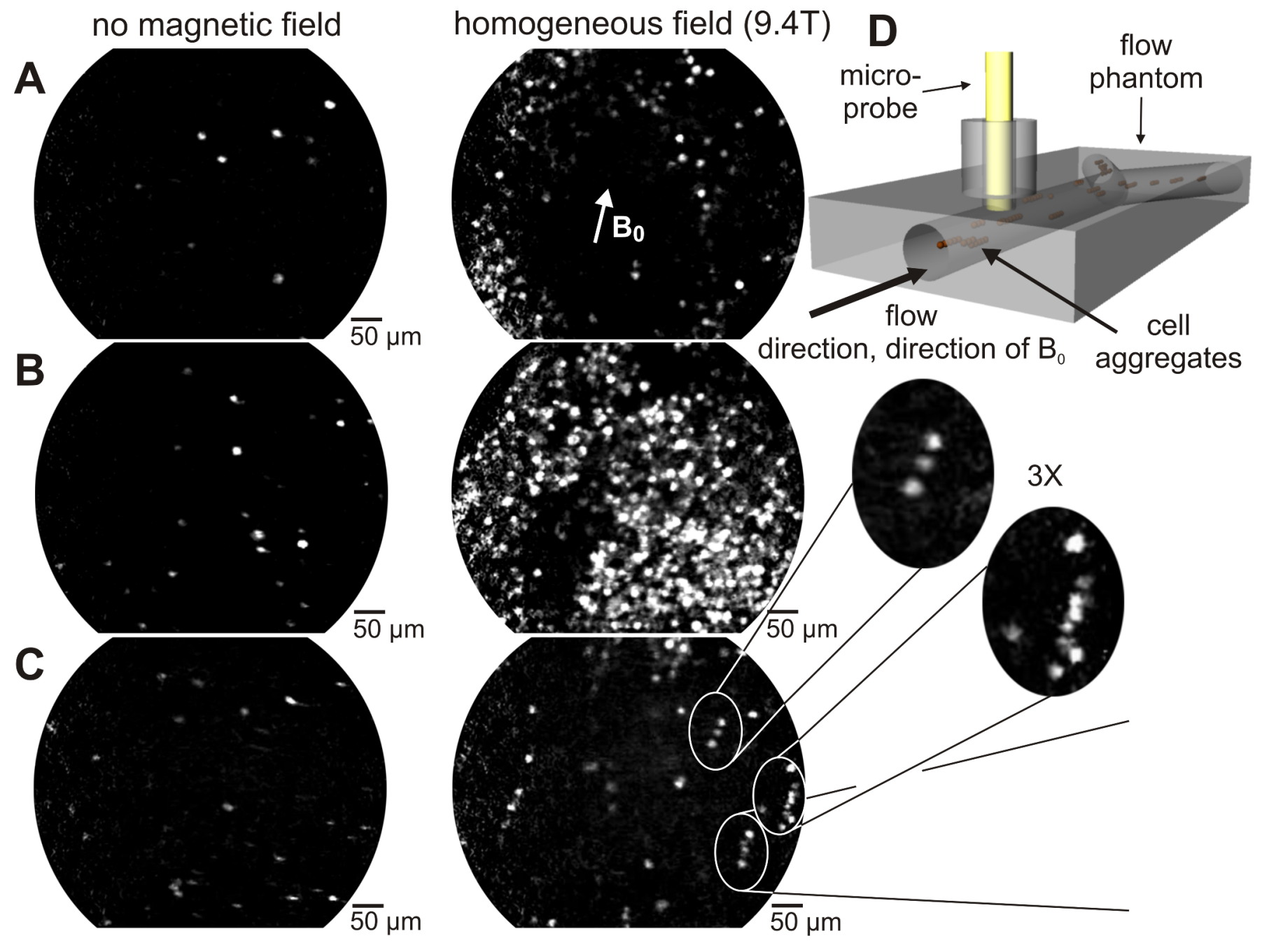

Figure 3 (figure3a_d_new.tif) 
A Targeting efficiency for different diameter ratios

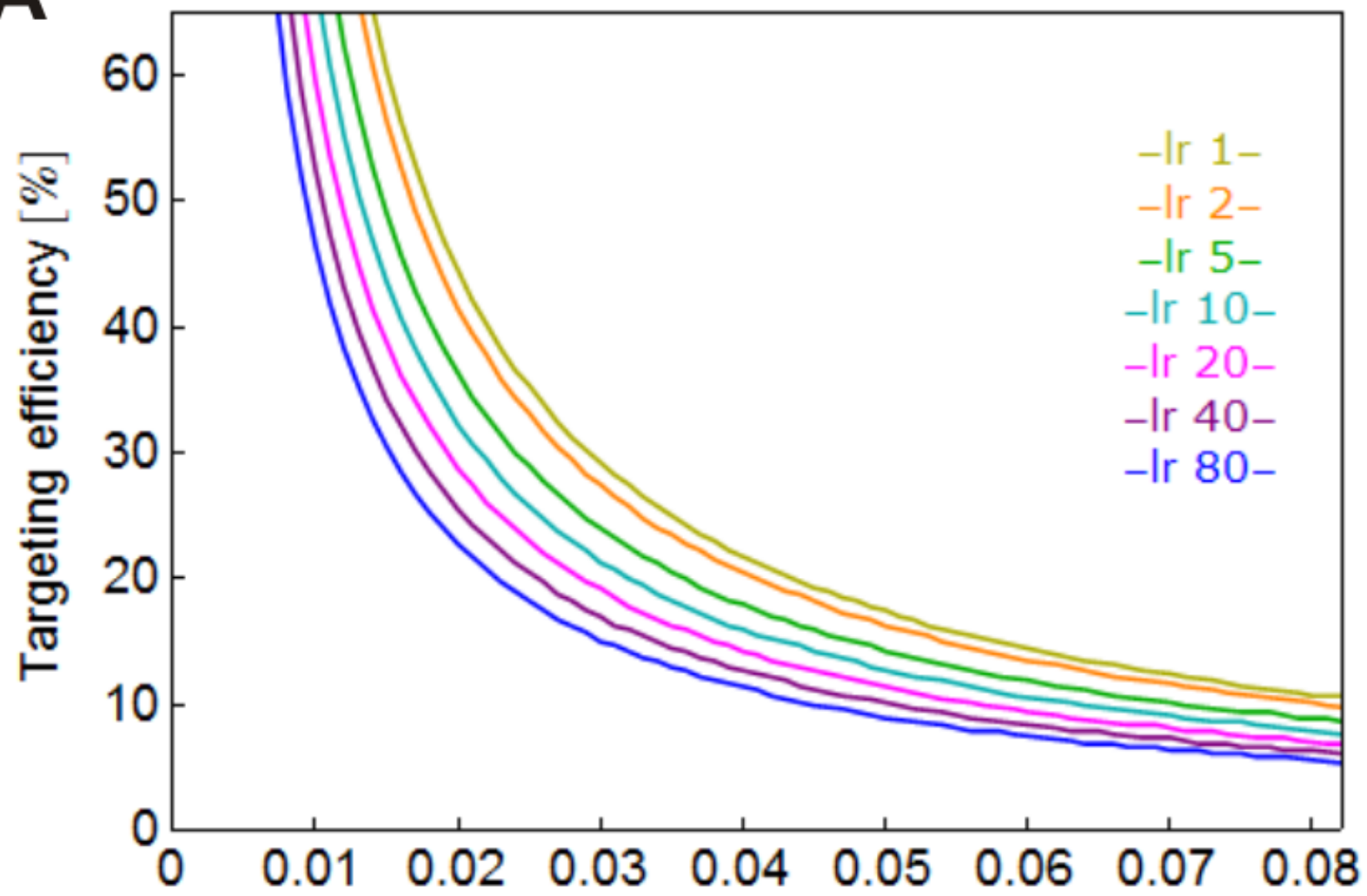

Fluid velocity $[\mathrm{m} / \mathrm{s}]$

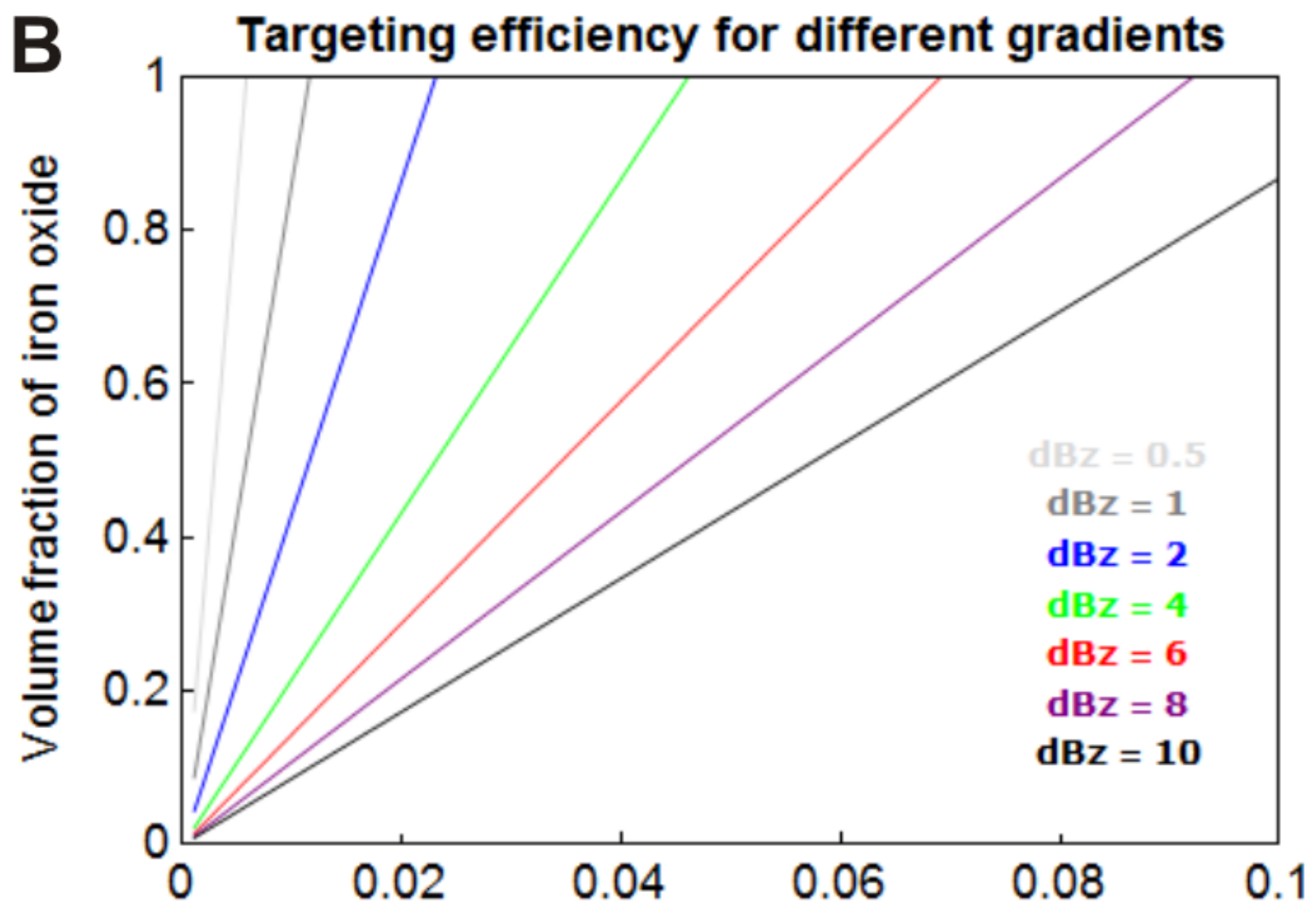

Fluid velocity $[\mathrm{m} / \mathrm{s}]$

Figure 4 (figure4a_b.tif) 